\title{
Memory and metamemory: Comparisons between patients with frontal lobe lesions and amnesic patients
}

\author{
JERI S. JANOWSKY, ARTHUR P. SHIMAMURA, and LARRY R. SQUIRE \\ Veterans Administration Medical Center, San Diego, California \\ and University of California, San Diego, La Jolla, California
}

\begin{abstract}
Metamemory refers to knowledge about one's own memory capabilities. The accuracy of metamemory judgments (i.e., feeling of knowing) was tested in patients with frontal lobe lesions and control subjects. Their performance was compared to other findings for 6 patients with Korsakoff's syndrome and 5 other patients with amnesia. In Experiment 1, subjects were presented sentences and then asked to recall key words from each sentence. They then judged their feeling of knowing for nonrecalled items in terms of how likely they thought they would be to recognize the key words on a subsequent recognition test. Patients with frontal lobe lesions exhibited impaired feeling of knowing when memory was weakened by imposing a 1-3-day delay between sentence presentation and recall. Experiment 2 tested feeling-of-knowing accuracy for nonrecalled general-information questions. On this test, patients with frontal lobe lesions performed normally. The metamemory deficit observed in Experiment 1 suggests that the frontal lobes contribute, at least in part, to metamemory judgments. The 5 (non-Korsakoff) amnesic patients had intact metamemory functions, but patients with Korsakoff's syndrome did not. These findings suggest that the metamemory impairment in patients with Korsakoff's syndrome is due, in part, to frontal lobe pathology.
\end{abstract}

Metamemory refers to knowledge of one's own memory capabilities and to knowledge of the strategies involved in memory performance. One aspect of metamemory is the feeling-of-knowing phenomenon-the ability to predict future success on a memory test (Gruneberg, 1983; Hart, 1965; Nelson, 1988). The study of amnesic patients has provided one useful way to explore the relation between feeling-of-knowing judgments and memory test performance (Shimamura \& Squire, 1986). Patients with Korsakoff's syndrome, who were severely impaired on conventional tests of recall and recognition memory, were also impaired in making metamemory judgments. Yet, other amnesic patients, who were as impaired on memory tests as were the Korsakoff patients, could nevertheless make metamemory judgments as accurately as could normal subjects. Thus, impaired feelng of knowing is not an obligatory feature of amnesia. Accordingly, the brain structures necessary for metamemory abilities are presumably different from the medial temporal and diencephalic structures that, when damaged, cause amnesia.

The research was supported by the Medical Research Service of the Veterans Administration, NIMH Grant MH24600, the Office of Naval Research, and NIMH Postdoctoral Fellowship MH09290 (to J. S. Janowsky). We thank Kim Rivero-Frink, Loni Shutler, Joyce Zouzounis, and Mark Kritchevsky for their assistance. J. S. Janowsky is now at the Psychology Department at the University of Oregon, Eugene, OR 97403-1226. Requests for reprints may be sent to L. R. Squire, Department of Psychiatry (V116-A), Veterans Administration Medical Center, 3350 La Jolla Village Dr., San Diego, CA 92161.
One possibility is that the metamemory deficits found in patients with Korsakoff's syndrome are due to frontal lobe pathology. There are several reasons for suggesting that metamemory abilities might depend on the integrity of the frontal lobes. First, patients with frontal lobe lesions exhibit deficits on certain tasks involving inferential, or metacognitive, judgments. For example, they have difficulty making estimates about everyday objects or experiences (e.g., "How tall is the average English woman?'; Shallice \& Evans, 1978). They also have difficulty estimating the price of objects (Smith \& Milner, 1984). Second, patients with Korsakoff's syndrome-but not other amnesic patients-exhibit cognitive deficits that are also observed in patients with circumscribed frontal lobe lesions (Janowsky, Shimamura, Kritchevsky, \& Squire, in press). Moreover, the severity of some cognitive deficits in Korsakoff patients (e.g., failure to release from proactive interference and poor temporal order judgments) correlated with performance on tests of frontal lobe function (Squire, 1982). Third, both patients with Korsakoff's syndrome (Butters \& Cermak, 1980; Squire \& Zouzounis, 1988; Talland, 1965) and patients with frontal lobe lesions (Blumer \& Benson, 1975; Luria, 1966) are often apathetic and lack insight into their disorder. Finally, cortical atrophy, and in particular frontal lobe atrophy, is present in patients with Korsakoff's syndrome (Carlen et al., 1981; Jacobson \& Lishman, 1987; Shimamura, Jernigan, \& Squire, 1988).

To test whether metamemory deficits depend on frontal lobe pathology, we assessed the accuracy of feeling- 
of-knowing judgments in patients with circumscribed frontal lobe lesions. We used the same feeling-of-knowing paradigms used by Shimamura and Squire (1986). In two experiments, subjects judged how likely they would be able to recognize items that they could not recall. They then took a recognition test to determine the accuracy of their judgments. We tested patients with frontal lobe lesions and a group of control subjects, and we compared their performance with that of two groups of amnesic patients-patients with Korsakoff's syndrome and 5 other patients with amnesia.

\section{EXPERIMENT 1}

\section{Method}

Subjects

Patients with frontal lobe lesions. Seven patients with lesions of the frontal lobes were identified by a review of medical records and CT scans at the VA Medical Center, San Diego, and at the University of California, San Diego Medical Center. Patients included were those who had lesions restricted to the frontal lobes and who had no other diagnoses likely to affect cognition or interfere with participation in the study (e.g., significant psychiatric disease, alcoholism). We studied 5 patients with unilateral frontal lobe lesions ( 2 left, 3 right) and 2 patients with bilateral lesions (see Figure 1). A detailed description of these patients appears elsewhere (Janowsky et al., in press).

These 7 patients ( 4 men and 3 women) averaged 64 years of age at the beginning of the study, had 13.0 years of education and an average Wechsler Adult Intelligence Scale-Revised (WAIS-R) Full Scale IQ score of 101.1. The 7 patients performed within the normal range on a test of immediate and delayed story recall, delayed diagram recall, and paired-associate learning (Janowsky et al., in press). In addition, Wechsler Memory Scale-Revised (WMS-R) scores were available for 6 of the 7 patients. Their average index scores were as follows: Attention and Concentration, 83.3; Verbal Memory, 100.7; Visual Memory, 90.5; General Memory, 95.7; Delayed Memory, 94.5. Each of the five indices for the WMS-R yields a mean score of 100 in the normal population with a standard deviation of 15 (Butters et al., 1988; Wechsler, 1987).

As reported elsewhere (Janowsky et al., in press), these patients were impaired on the Wisconsin Card Sort Test (Berg, 1948; Heaton, 1981), a standard test of frontal lobe dysfunction (number of categories, mean $=2.1$, range $=0-5$; percent of perseverative errors, mean $=41.6$, range $=10-98$ ). In addition, they were impaired on the 37-point Initiation and Perseveration index of the Dementia Rating Scale (Mattis, 1976; mean $=31.9$, range $=26-36$ ). Finally, the patients with left and bilateral frontal lobe lesions (but not patients with right frontal lobe lesions) were impaired on the Verbal Fluency Test (Benton \& Hamsher, 1976; mean number of words produced $=21.5$, range $=17-35$ ). Additional neuropsychological data for these patients can be found in Janowsky et al.
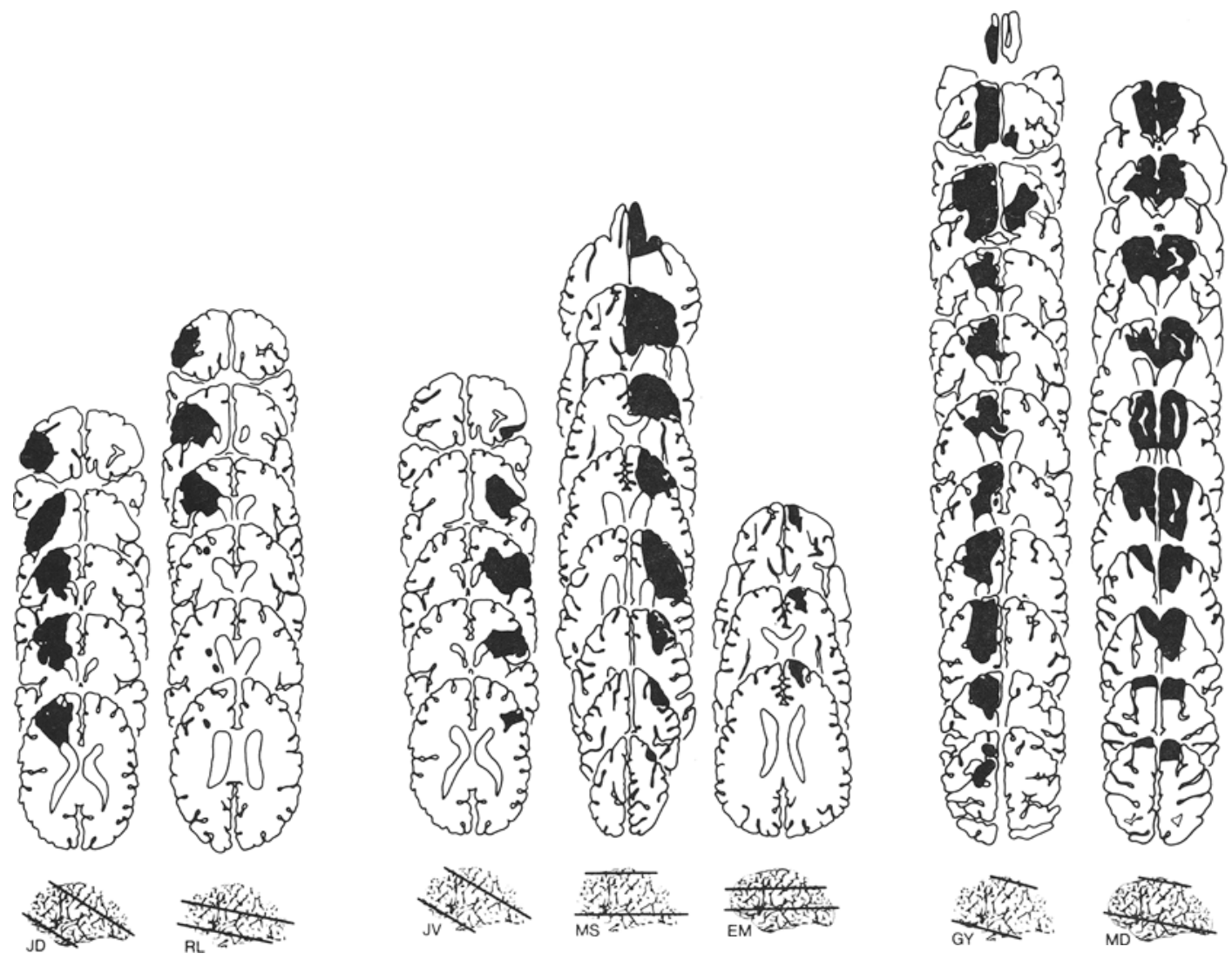

Figure 1. Reconstructions from CT or MRI brain scans of the frontal lobe damage (in black) for each patient in the study, using the method of $\mathrm{H}$. Damasio (1983, and persongl communication). The most ventral section is shown at the top. The lateral view below each construction shows the angle of the horizontal sections and the locations of the most dorsal and ventral sections. 
(in press). Testing occurred between February, 1987, and January, 1988 .

Healthy control subjects. Eight subjects ( 5 men and 3 women) served as control subjects for the patients with frontal lobe lesions. They were matched to the study patients with respect to age (mean $=60.6$ years) and education (mean $=14.3$ years). They were also matched to the study patients on the basis of two WAIS-R subtest scores, Information (control subjects, mean $=22.6$; study patients, mean $=21.9$ ) and Vocabulary (control subjects, mean $=55.8$; study patients, mean $=53.7$ ).

Patients with Korsakoffs syndrome. Data for 6 patients with Korsakoff's syndrome ( 4 men and 2 women) have been published previously (Shimamura \& Squire, 1986) and are presented here for comparison purposes. These 6 patients averaged 45.3 years of age, with 11.8 years of education. Their average WAIS-R Full Scale IQ score was 97.1 . Their average index scores on the recently available WMS-R were as follows: Attention and Concentration, 87.7; Verbal Memory, 72.0; Visual Memory, 69.7; General Memory, 64.8; Delayed Memory, 55.7. Additional neuropsychological data for these same 6 patients can be found elsewhere (Squire \& Shimamura, 1986).

Other patients with amnesia. Data are presented for 5 other amnesic patients. Three of these patients became amnesic after an episode of anoxia or ischemia (A.B., G.D., and L.M.), and data for these patients were reported previously (Shimamura \& Squire, 1986). Subsequently, 2 additional patients (W.H. and M.G.) were tested. W.H. became amnesic in 1986, but without a known precipitating event. Preliminary magnetic resonance (MR) scans have identified bilateral medial temporal pathology. M.G. became amnesic in 1986 following a bilateral thalamic infarction. As a group, the 5 patients averaged 54.6 years of age at the beginning of the study, with an average educational level of 15.6 years. Their average WAIS-R Full Scale IQ was 109.2. On the WMS-R, the average index scores were as follows: Attention and Concentration, 105.4; Verbal Memory, 77.8; Visual Memory, 81.2; General Memory, 73.0; Delayed Memory, 55.0. Additional neuropsychological data for these 5 patients can be found in Janowsky et al. (in press).

\section{Procedure}

The procedure was the same as was used in a previous study of feeling-of-knowing accuracy in amnesic patients (Shimamura \& Squire, 1986, Experiment 2). Patients with frontal lobe lesions and control subjects were presented 24 sentences for study (e.g., " At the museum we saw some ancient relics made of clay."). The sentences were presented on cards and were also read by the experimenter. Twelve of the sentences were presented once, and the other 12 sentences were presented twice for a total of 36 presentations. The subjects were asked to study the sentences so that they would remember them later.

Recall phase. After a 5-min delay, recall was assessed by asking the subjects to recall the missing word in each of the 24 sentences (e.g., "At the museum we saw some ancient relics made of _..."). Also, 8 new sentences (with a key word missing in each case) were included that had not been presented for study. The subjects were instructed to guess if they were uncertain of the correct word. Also, they were told that some of the test items might be ones that they had not seen previously.

Feeling-of-knowing phase. Immediately following the recall phase, the subjects were asked to make feeling-of-knowing judgments. For each nonrecalled item, as well as for each of the 8 new test items, the subjects rated their feeling of knowing on a 4-point scale (high, medium, low, pure guess). Specifically, the subjects were shown each sentence and were asked to judge how likely they would be able to recognize the missing word if some choices were given. After placing the nonrecalled sentences and the 8 new sentences into one of the four feeling-of-knowing categories, the subjects rank-ordered the sentences within each rating category accord- ing to their feeling of knowing. Thus, at the end of this phase, all the sentences had been ranked, from the one judged as having the highest feeling of knowing to the one judged as having the lowest feeling of knowing.

Recognition phase. Immediately following the feeling-of-knowing phase, the subjects were given a seven-alternative, forced-choice recognition test for all 24 study sentences and the 8 new sentences. Eight alternatives were available for each question. If a subject gave one of the eight alternatives as an incorrect response during the initial recall phase, that alternative was omitted from the recognition test. Otherwise, one of the incorrect alternatives was randomly omitted. Thus, there were always seven possible choices for the blank in each sentence. Recognition responses to the 8 new sentences (those not presented for study) were scored as a 0 . Feeling-ofknowing accuracy was then calculated using a nonparametric correlation (gamma) between the feeling-of-knowing ranking and recognition performance (Hays, 1973; Nelson, 1984).

In addition to testing the patients with frontal lobe lesions and the control subjects after a 5-min delay, we repeated the experiment with these two groups using a similar set of materials and a 1-3-day delay. This longer retention interval was used in order to test feeling-of-knowing judgments at a time when memory performance was weak. Specifically, the 1-3-day-delay condition measured feeling-of-knowing accuracy in patients with frontal lobe lesions at a time when their memory performance matched that of the amnesic patients tested after the 5-min delay. These two test conditions (5-min and 1-3-day delays) were separated by an average of 5 weeks (range $=1-16$ weeks).

\section{Results}

\section{Recall}

Figure 2 shows the recall performance of the patients with frontal lobe lesions and the control subjects in the 5-min and 1-3-day-delay conditions, as well as the performance of amnesic patients. Performance was first assessed using a $2 \times 2$ ANOVA with groups (frontal patients

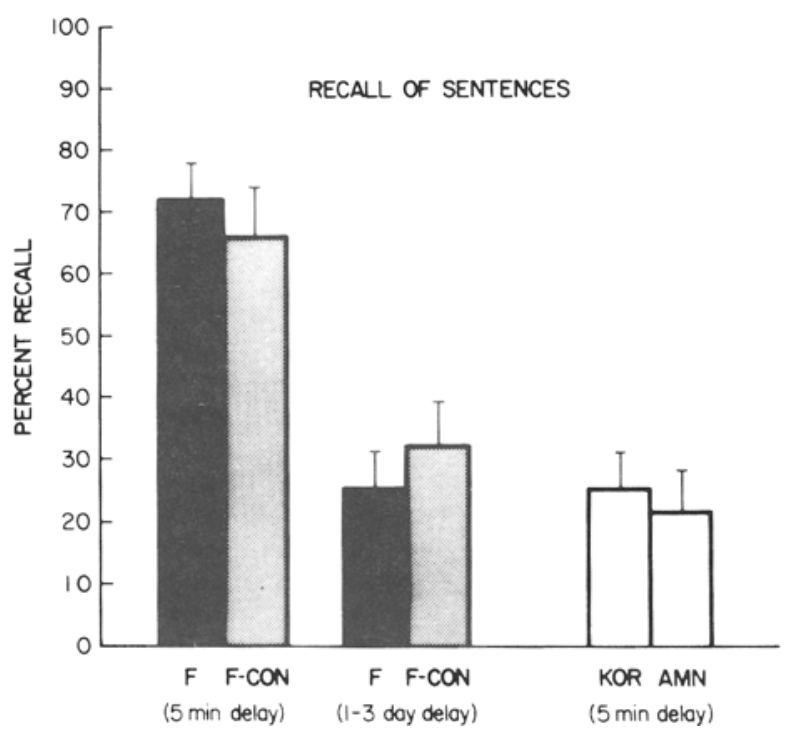

Figure 2. Performance of the subjects who studied 24 sentences and were then asked to recall a missing part of each sentence. $F$ $=$ patients with frontal lobe lesions; F-CON = control subjects for frontal patients; KOR = patients with KorsakofPs syndrome; AMN $=$ other patients with amnesia. Bars show standard error of the mean. 
vs. control subjects) and delay (5 $\mathrm{min}$ and 1-3 days) as independent variables. Recall performance by the patients with frontal lobe lesions was similar to that of control subjects $[F(1,13)=.01, p>.10]$. There was a significant main effect of delay $[F(1,13)=112.8, p<.01]$, showing that both groups performed better in the 5-min-delay condition than they did in the 1-3-day-delay condition. The group $\times$ delay interaction was not signfiicant $[F(1,13)$ $=2.85, p>.10$ ], demonstrating that both groups were affected equally by the delay.

An analysis of presentation frequency showed that the patients with frontal lobe lesions and their control group were better at recalling sentences that had been presented twice than they were at recalling sentences that had been presented only once $[F(1,13)=12.2, p<.05]$. The marginal interaction between group and presentation frequency $[F(1,13)=3.8, p=.07]$ suggested that, when a sentence was presented twice instead of once, the patients with frontal lobe lesions benefited somewhat more than did their control group (58\% vs. $38 \%$ correct for the patients with frontal lobe lesions; $53 \%$ vs. $47 \%$ correct for the control subjects).

Recall performance of the patients with frontal lobe lesions at the 1-3-day delay was similar to the performance of the 6 patients with Korsakoff's syndrome and the 5 other patients with amnesia, who were tested after a 5 -min delay $(t \mathrm{~s}<1.0, p \mathrm{~s}>.10)$. The 1-3-day-delay score was $25 \%$ correct for the patients with frontal lobe lesions, $25 \%$ correct for the patients with Korsakoff's syndrome, and $21 \%$ correct for the other patients with amnesia. Both amnesic groups recalled sentences presented twice better than they recalled sentences presented only once [ $31 \%$ vs. $17 \%$ for the patients with Korsakoff's syndrome, $t(5)=4.47, p<.05 ; 30 \%$ vs. $12 \%$ for the other patients with amnesia, $t(4)=2.56, p=.06$ ]

\section{Recognition}

Recognition performance for all 24 study sentences (recalled and nonrecalled sentences) was similar for the patients with frontal lobe lesions and their control group $[F(1,13)=.18, p>.10]$. The patients with frontal lobe lesions and the control subjects recognized more words in the 5-min-delay condition ( $83 \%$ and $82 \%$, respectively) than they did in the 1-3-day-delay condition [48\% and $56 \%$, respectively; $F(1,13)=87.1, p<.05]$. There was no group $\times$ delay interaction $[F(1,13)=2.1, p>.10]$. Also, the subjects were better at recognizing words from sentences that had been presented twice than they were at recognizing words from sentences that had been presented only once $[F(1,13)=27.8, p<.05]$. Presentation frequency benefited the performance of the patients with frontal lobe lesions more than it did the control subjects, as indicated by a significant group $\times$ presentation frequency interaction $[F(1,13)=10.5, p<.05]$. Perhaps patients with frontal lobe lesions especially benefit from repeated presentations because they have some difficulty attending to the material. As with recall performance, the recognition score obtained by the patients with frontal lobe lesions at the 1-3-day delay (48\%) was similar to the recognition scores obtained by both the patients with Korsakoff's syndrome $(47 \%)$ and the other patients with amnesia (mean $=37 \%, t \mathrm{~s}<1.50, p>.10$ ). The effect of presentation frequency did not reach significance for either amnesic group ( $t \mathrm{~s}<1.1, p \mathrm{~s}>.10)$.

Figure 3 shows recognition performance for the nonrecalled sentences-that is, those sentences for which the subjects made feeling-of-knowing judgments. The patients with frontal lobe lesions performed similarly to control subjects in both the 5-min-delay and 1-3-day-delay conditions $[F(1,13)=.69, p>.10]$. Although the effect of delay did not reach significance $[F(1,13)=3.0, p=.11]$, both groups recognized fewer items after the 1-3-day delay (32\% for the patients with frontal lobe lesions, $43 \%$ for the control subjects) than they did after the 5-min delay (47\% and $53 \%$, respectively). There was no group $\times$ delay interaction $[F(1,13)=.10, p>.10]$. Finally, the recognition score obtained by the patients with frontal lobe lesions at the 1-3-day delay $(32 \%)$ was similar to the recognition scores obtained by the patients with Korsakoff's syndrome $(31 \%)$ and the other patients with amnesia $(36 \%, t \mathrm{~s}<1.0, p \mathrm{~s}>.10]$.

\section{Feeling of Knowing}

Figure 4 shows feeling-of-knowing accuracy, which was assessed with a nonparametric (gamma) measure that correlated each subject's feeling-of-knowing rankings with his/her recognition test performance. Across delay conditions, there was no effect of group [frontal patients vs. control subjects; $F(1,12)=2.22, p>.10$. There was a significant effect of delay $[F(1,12)=11.7, p<.05]$, indicating that feeling-of-knowing accuracy was better in

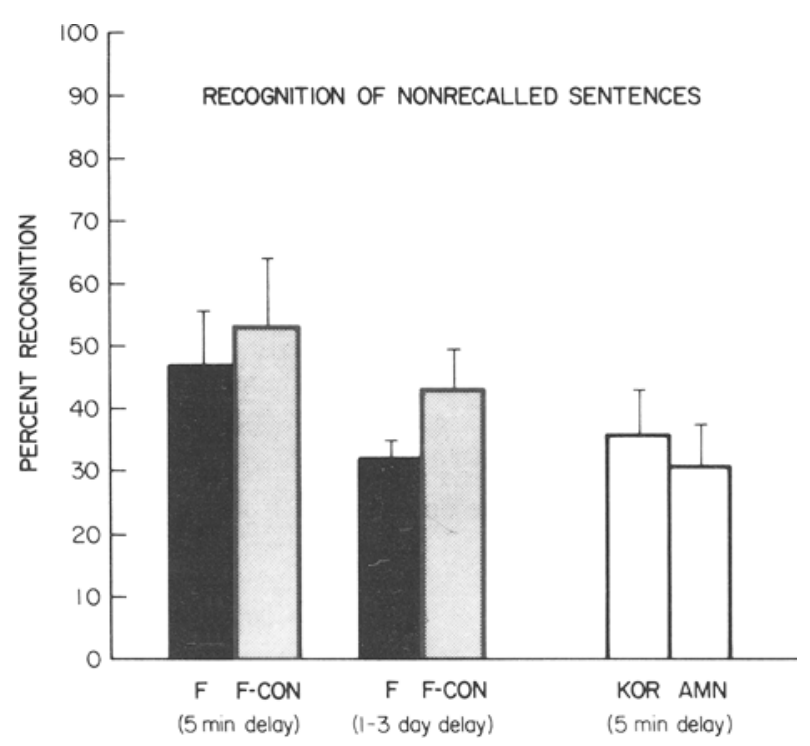

Figure 3. Recognition memory (seven-alternative, forced-choice) for the sentence information that could not be recalled. $F=$ patients with frontal lobe lesions; F-CON = control subjects for frontal patients; $\mathbf{K O R}=$ patients with Korsakoff's syndrome; $\mathbf{A M N}=$ other patients with amnesia. Bars show standard error of the mean. 


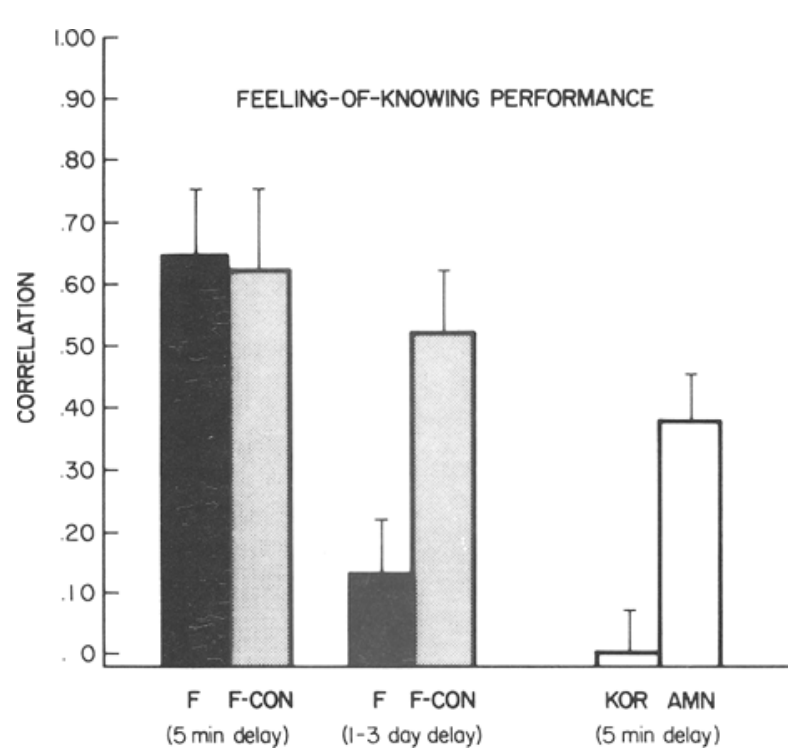

Figure 4. Feeling-of-knowing performance for the sentence information that could not be recalled. Feeling-of-knowing accuracy was calculated by correlating feeling-of-knowing ranking with subsequent recognition performance. $F$ = patients with frontal lobe lesions; $F$ CON = control subjects for frontal patients; $K O R$ = patients with Korsakoffs syndrome; AMN = other patients with amnesia. Bars show standard error of the mean.

the short-delay condition than in the long-delay condition. Importantly, there was a significant group $\times$ delay interaction $[F(1,12)=6.6, p<.05]$. Specifically, feelingof-knowing performance in the 5-min-delay condition was similar for the patients with frontal lobe lesions and the control subjects (average gamma correlation $=.64$ and .62 , respectively). Yet, in the 1-3-day-delay condition, the patients with frontal lobe lesions performed more poorly than did the control subjects [.13 and .52 , respectively; $t(13)=2.95, p<.05$ ]. In fact, the feeling-ofknowing performance of the patients with frontal lobe lesions in the 1-3-day-delay condition did not differ significantly from chance $[t(6)=1.33, p>.10]$.

The patients with frontal lobe lesions were slightly more likely to overestimate than underestimate their subsequent memory performance. For the items they placed in the high and medium feeling-of-knowing categories, they achieved only $27 \%$ correct, while the control subjects achieved $42 \%$ correct. For items placed in the low and guess categories, the patients with frontal lobe lesions and the control subjects achieved $14 \%$ and $19 \%$ correct, respectively.

Due to the variability in the locus and extent of damage in this small group of patients, it was not possible to explore statistically how feeling-of-knowing accuracy was affected by site and size of lesions. It is worth pointing out, however, that the 2 patients with bilateral frontal lesions, who achieved 0 and 1 categories on the Wisconsin Card Sort Test, also achieved very low scores on the feeling-of-knowing test (correlations of +.11 and -.09 , respectively).

The low feeling-of-knowing score obtained by the patients with frontal lobe lesions in the 1-3-day-delay conditon was similar to the score obtained by the patients with Korsakoff's syndrome $[t(11)=1.10, p>.10]$, who also were unable to make feeling-of-knowing judgments at above-chance levels (correlation $=-.007$; Shimamura \& Squire, 1986). By contrast, the other patients with amnesia performed at above-chance levels [average gamma correlation $=.38, t(4)=5.6, p<.05]$. Their feeling-of-knowing accuracy was significantly better than that of the patients with Korsakoff's syndrome $[t(9)=$ $3.8, p<.05]$ and marginally better than that of the patients with frontal lobe lesions $[t(10)=2.07, p=.07]$.

The feeling-of-knowing scores indicated that the judgments made by the patients with frontal lobe lesions remained impaired even when the correlations between recognition and feeling-of-knowing ranking excluded the 8 sentences that had never been presented for study. These recalculated gamma correlations were .04 for the patients with frontal lobe lesions and .42 for the control subjects in the delayed condition $[t(13)=2.76, p<.05]$. This analysis shows that impaired feeling-of-knowing accuracy did not depend on requiring the subjects to make judgments about sentences that they had not studied previously.

In summary, the patients with frontal lobe lesions and the control subjects exhibited comparable recall and recognition memory for words in sentences. Although the patients with frontal lobe lesions exhibited intact feeling of knowing when tested after a 5-min delay, they exhibited severe feeling-of-knowing impairment when tested after a 1-3-day delay. Indeed, after a 1-3-day delay, feelingof-knowing judgments by the patients with frontal lobe lesions were not significantly above chance. Previously, the patients with Korsakoff's syndrome, but not other amnesic patients, were also found to exhibit impaired feelingof-knowing judgments. The findings from Experiment 1 suggest that the ability to make accurate feeling-ofknowing judgments depends, at least in part, on the integrity of the frontal lobes.

\section{EXPERIMENT 2}

In a previous study (Shimamura \& Squire, 1986), patients with Korsakoff's syndrome, but not other amnesic patients, exhibited impaired feeling of knowing for factual information that could not be recalled. Experiment 2 investigated feeling-of-knowing performance of patients with frontal lobe lesions on this same task.

\section{Method}

\section{Subjects}

Patients with frontal lobe lesions. See Experiment 1.

Healthy control subjects. Six of the 8 control subjects from Experiment 1 and 2 additional subjects ( 4 men and 4 women) served as the control subjects in Experiment 2. They were matched to the 
patients with frontal lobe lesions with respect to age (mean $=\mathbf{5 9 . 9}$ years) and education (mean $=13.7$ years). The mean scores on the Information and Vocabulary subtests of the WAIS-R were 21.5 and 53.9, respectively (frontal patients, 21.9 and 53.7).

Patients with Korsakoff's syndrome. Previously published data for 8 patients with Korsakoff's syndrome ( 5 men and 3 women) are included here for comparison purposes (Shimamura \& Squire, 1986). Comparison data for 6 of these 8 patients were also presented in Experiment 1. The 8 patients averaged 54.0 years of age, with 12.3 years of education. They had an average WAIS Full Scale IQ score of 102.6 and an average WMS score of 78.

Other patients with amnesia. See Experiment 1.

\section{Procedure}

The procedure used in Experiment 2 was identical to the one used in our previous study of feeling-of-knowing accuracy for generalinformation questions (Shimamura \& Squire, 1986, Experiment 1). A set of 100 general-information questions (e.g., What is the name of the project which developed the atomic bomb during World War II? [Manhattan]) were selected from a pool of questions developed by Nelson and Narens (1980). The degree of difficulty of the questions varied from a recall probability for college students of .004 to a recall probability of .97 .

Recall phase. The subjects were first asked to recall the answers to general-information questions. The experimenter showed the subject each question on a card and read the question aloud. The recall phase continued until the subject missed a total of 24 questions (including errors of omission and commission).

Feeling-of-knowing phase. Immediately following the recall phase, the subjects were asked to rate each of the 24 nonrecalled questions according to their feeling of knowing (high, medium, low, pure guess). Just as in Experiment 1, the subjects were shown each item and asked to judge how likely they would be able to recognize the correct answer if some choices were given. After each question was placed into one of four feeling-of-knowing categories, the subjects rank-ordered their feeling of knowing within each category. Thus, at the end of this phase all questions had been ranked from the question judged as having the highest feeling of knowing to the question judged as having the lowest feeling of knowing.

Recognition phase. Immediately after the feeling-of-knowing phase, a seven-alternative, forced-choice recognition test was administered for the 24 questions. Recognition alternatives were obtained from the FACTRETRIEVAL computer program (Shimamura, Landwehr, \& Nelson, 1981). Eight alternatives were available for each question. If a subject gave one of the eight alternatives as an incorrect response during the initial recall phase, that alternative was omitted from the recogntion test. Otherwise, one of the incorrect alternatives was randomly omitted for each question. Thus, in all cases, the subjects were asked to choose the correct answer from seven alternatives. As in Experiment 1, feelingof-knowing accuracy was calculated using a nonparametric correlation (gamma) between feeling-of-knowing ranking and recognition performance.

A second test was also administered in order to assess feeling of knowing for very difficult facts. A set of 54 difficult generalinformation questions was assembled from the pool of generalinformation questions described above. On the basis of the norms, the recall probability for these difficult questions ranged from .004 to .31 . We administered the second test to 6 of the 7 patients with frontal lobe lesions approximately 7 months after the first test. The 7 th subject was not available for testing.

\section{Results}

\section{Recall}

Figure 5 shows the recall performance of the patients with frontal lobe lesions and the control subjects, as well

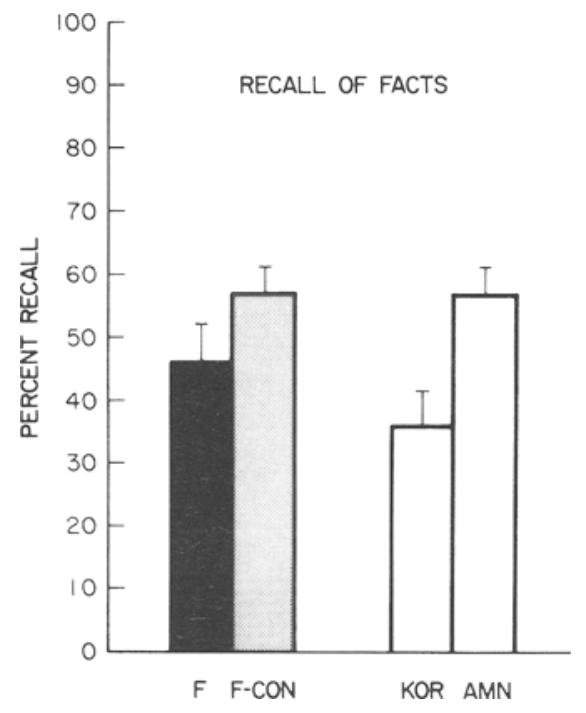

Figure 5. Recall performance for general information questions. The subjects were asked questions until they had failed 24 items. $\mathbf{F}=$ patients with frontal lobe lesions; $\mathbf{F}-\mathbf{C O N}=$ control subjects for frontal patients; KOR = patients with Korsakoffs syndrome; AMN = other patients with amnesia. Bars show standard error of the mean.

as the performance of the amnesic patients. The patients with frontal lobe lesions performed similarly to their control subjects [ $46 \%$ and $57 \%$, respectively; $t(13)=1.47$, $p>.10]$. The patients with Korsakoff's syndrome were poor at recalling general-information facts on this test (Shimamura \& Squire, 1986). Figure 5 shows that the recall score obtained by the patients with frontal lobe lesions $(46 \%)$ was numerically higher than the score of the patients with Korsakoff's syndrome (36\%) and numerically lower than the score of the other patients with amnesia (57\%). These differences were not statistically significant $(t \mathrm{~s}<1.42, p \mathrm{~s}>.10)$.

\section{Recognition}

Figure 6 shows recognition performance for the 24 nonrecalled facts. The patients with frontal lobe lesions performed similarly to their control subjects [ $42 \%$ and $52 \%$, respectively; $t(13)=1.62, p>.10]$. The patients with Korsakoff's syndrome (47\%) performed worse than did the other patients with amnesia $[63 \% ; t(10)=2.83$, $p<.05]$ and similarly to the patients with frontal lobe lesions $[t(13)=.66, p>.10]$.

\section{Feeling of Knowing}

Figure 6 also shows feeling-of-knowing accuracy as measured by the correlation between feeling-of-knowing ranking and recognition performance. The patients with frontal lobe lesions were able to make feeling-of-knowing judgments for factual information as well as did their control group [average gamma correlation $=.41$ and .43 , respectively; $t(13)=.31, p>.10$ ]. One patient with bilateral frontal lobe lesions performed worse than did the rest of the patients and all of the control subjects (.23), 


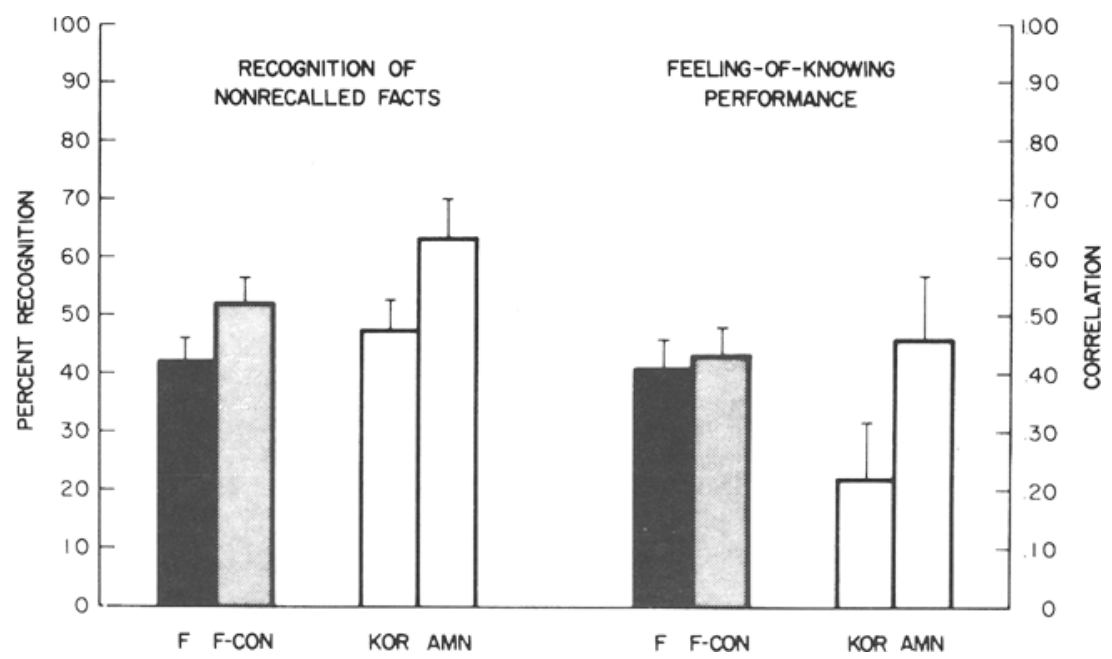

Figure 6. Recognition memory (seven-alternative, forced-choice) and feeling-of-knowing accuracy for 24 nonrecalled facts. Feeling-of-knowing accuracy was calculated by correlating feeling-of-knowing ranking with subsequent recognition performance. $F=$ patients with frontal lobe lesions; F-CON = control subjects for frontal patients; KOR $=$ patients with Korsakoffs syndrome; $\mathbf{A M N}=$ other patients with amnesia. Bars show standard error of the mean.

while the other subject with bilateral lesions performed normally (.45). In contrast, as reported previously (Shimamura \& Squire, 1986), the patients with Korsakoff's syndrome, but not other amnesic patients, performed poorly on this feeling-of-knowing task.

In the second test, which used more difficult questions, recall performance of the patients with frontal lobe lesions was only $18 \%$ and recognition performance was $33 \%$. Despite the fact that the patients with frontal lobe lesions now performed even more poorly than did the patients with Korsakoff's syndrome on the first test (recall score $=36 \%$, recognition score $=47 \%$ ), their feelingof-knowing accuracy remained quite good (correlation = .41). Thus, the patients with frontal lobe lesions were able to make feeling-of-knowing judgments about general factual information across a wide range of item difficulty.

\section{DISCUSSION}

Experiment 1 showed that patients with frontal lobe lesions were unable to make feeling-of-knowing judgments for newly learned sentences. Specifically, when recall and recognition memory for the sentences was weakened by imposing a delay between the learning and the recall test, the control subjects obtained high feeling-of-knowing scores, but the patients with frontal lobe lesions performed at chance levels. A deficit in feeling of knowing for newly learned sentences was also reported previously for patients with Korsakoff's syndrome, but not for other amnesic patients (Shimamura \& Squire, 1986). Experiment 2 showed that patients with frontal lobe lesions exhibited intact feeling-of-knowing ability for previously learned factual information. Patients with Korsakoff's syndrome, but not other amnesic patients, were poor at making these feelingof-knowing judgments (Shimamura \& Squire, 1986).

The poor feeling-of-knowing performance by the patients with frontal lobe lesions is consistent with their deficits on other metacognitive tasks. Thus, patients with frontal lobe lesions have difficulty on tasks requiring the organization of responses (Petrides \& Milner, 1982) and the organization of information into categories (Incisa della Rochetta, 1986). They are poor at making inferences and estimates about common objects or events (Shallice \& Evans, 1978), at estimating prices of objects (Smith \& Milner, 1984), and at estimating the frequency or recency of occurrence (Milner, Petrides, \& Smith, 1985; Smith \& Milner, 1988). These observations suggest that impaired feeling of knowing may not be a specific cognitive disorder. Rather the frontal lobes may mediate processes required to make a wide variety of metacognitive judgments, including feeling-of-knowing judgments.

The patients with frontal lobe lesions did not exhibit a feeling-of-knowing impairment on all of the tests used in the present study. Specifically, they had accurate feeling of knowing for factual information, much of which would have been learned long ago. One possibility is that patients with frontal lobe lesions have impaired feelng of knowing only for information learned after the frontal lobe injury. This possibility seems unlikely because such patients fail on many other tests that require estimates about items encountered premorbidly (e.g., estimates about everyday objects or price estimations; see Shallice \& Evans, 1978; Smith \& Milner, 1984). Another possibility is that it is easier to base metamemory judgments on memory for factual information than it is to base them on memory for words in sentences. The factual questions 
used in Experiment 2 covered a variety of generalinformation topics learned long ago and were likely to be well integrated into a person's knowledge. By contrast, the sentence material used in Experiment 1 was more arbitrary and homogeneous, and was not well related to existing knowledge.

Other characteristics of test material might also determine when feeling-of-knowing judgments are most difficult and, correspondingly, when impaired performance will most readily appear. In Experiment 1, the deficit appeared only in the delay condition, when memory performance was weakened to match the performance of the two amnesic groups. Feeling-of-knowing performance was intact in the 5-min-delay condition. However, in the 5-min-delay condition, performance was so good that there were few nonrecalled sentences with which to estimate feeling-of-knowing ability (average $=6.9 / 24$ ). Therefore, the subjects based their feeling-of-knowing judgments primarily on their unfamiliarity for the 8 new sentences and on their better familiarity for a few recently presented nonrecalled sentences. Accordingly, it is possible that the 5-min-delay condition did not provide a sufficiently sensitive test of metamemory abilities. In Experiment 2 , a set of very difficult facts was administered in an attempt to make the tasks more difficult. However, some of these facts might never have been learned in the first place, so that the subjects based their feeling-ofknowing performance on facts that were completely unfamiliar and on a few other facts that were more familiar. Accordingly, some difficult facts might have been easy for the subjects to treat as low in feeling of knowing (e.g., as pure guesses), just as the 8 new sentences in the 5-mindelay condition of Experiment 1 were easy to treat as guesses.

The finding of a metamemory deficit in the patients with frontal lobe lesions suggests that the metamemory impairment exhibited by patients with Korsakoff's syndrome may also be due, at least in part, to frontal lobe pathology. In fact, the patients with Korsakoff's syndrome who participated in this study do have frontal lobe atrophy, as demonstrated by a quantitative CT technique (Shimamura et al., 1988). Compared to the healthy control subjects, the patients with Korsakoff's syndrome exhibited increased fluid volume bilaterally in the frontal lobe. Moreover, patients with frontal lobe lesions and patients with Korsakoff's syndrome share other cognitive deficits in addition to impaired metamemory. Both have deficits on the Initiation-Perserveration subscale of the Dementia Rating Scale and both perform poorly on the Wisconsin Card Sort Test (Janowsky et al., in press; Jetter, Poser, Freeman, \& Markowitsch, 1986). As discussed elsewhere (Janowsky et al., in press), all of these deficits are likely to be related to frontal lobe pathology in these patients.

Taken together, evidence from this study and from a previous study (Shimamura \& Squire, 1986) shows that, while both patients with frontal lobe lesions and patients with Korsakoff's syndrome have a metamemory deficit, patients with Korsakoff's syndrome have a more pervasive deficit. The patients with Korsakoff's syndrome were unable to make accurate feeling-of-knowing judgments about sentences and factual information, whereas the patients with frontal lobe lesions were impaired only with sentences, and then only in the delay condition. One possibility is that the diencephalic lesions found in the patients with Korsakoff's syndrome (Shimamura et al., 1988) contribute to their metamemory impairment. It should be noted, however, that Patient N.A., who is amnesic due to a left diencephalic lesion (Squire, Amaral, Zola-Morgan, Kritchevsky, \& Press, 1987), showed normal feeling-of-knowing performance (Shimamura \& Squire, 1986). Also, in the present study, Patient M.G., who has bilateral thalamic lesions, showed normal feelingof-knowing performance. A second possibility is that the patients with Korsakoff's syndrome have more widespread damage or more severe damage to the frontal lobes than do the patients with circumscribed frontal lobe lesions.

Perhaps a more likely possibility is that frontal lobe lesions and memory impairment together produce a more severe metamemory deficit than do frontal lobe lesions alone. Nelson, Gerler, and Narens (1984) suggested two different means by which feeling-of-knowing judgments might be made. One method requires access to specific item information in memory (trace-access mechanisms). The second depends on inferential mechanisms that operate on contextual knowledge and other related knowledge. Patients with frontal lobe lesions may show feeling-ofknowing deficits due to failure of inferential abilities. However, because these patients are not amnesic, they may sometimes be able to base their feeling-of-knowing judgments on preserved trace-access mechanisms. Patients with Korsakoff's syndrome may have particularly poor feeling-of-knowing ability because they have impaired inferential mechanisms due to frontal lobe damage, as well as impaired trace-access mechanisms due to diencephalic damage. Patients with anoxic-ischemic amnesia and other non-Korsakoff patients have a feeling-of-knowing ability commensurate with their reduced level of performance on memory tasks (i.e., their ability is as good as that of control subjects who are matched for memory strength).

In summary, this study suggests that the frontal lobes make an essential contribution to metamemory ability. Because patients with frontal lobe lesions do not exhibit memory impairment, the present study demonstrates that metamemory deficits can occur in the absence of amnesia. The finding that patients with frontal lobe lesions and patients with Korsakoff's syndrome exhibit a feeling-ofknowing impairment, but that other amnesic patients do not, strengthens the view that memory and metamemory are dissociable processes.

\section{REFERENCES}

Benton, A. L., \& HAMSher, K. DES. (1976). Multilingual aphasia examination. Iowa City: University of Iowa Press.

BERG, E. A. (1948). A simple objective test for measuring flexibility in thinking. Journal of General Psychology, 39, 15-22. 
Blumer, D., Benson, D. F. (1975). Personality changes with frontal and temporal lobe lesions. In D. F. Benson \& D. Blumer (Eds.), Psychiatric aspects of neurologic disease (Vol. 1, pp. 151-170). New York: Grune \& Stratton.

ButTERs, N., \& CERMAK, L. S. (1980). Alcoholic Korsakoff's syndrome: An information processing approach to amnesia. New York: Academic Press.

Butters, N., Salmon, D., Cullum, M., Cairns, P., Troster, A., Jacobs, D., Moss, M., Cermak, L. (1988). Differentiation of amnesic and demented patients with the WMS-R. Clinical Neuropsychologist, 2, 133-148.

Carlen, P. L., Wilkinson, D. A., Wortzman, G., Holgate, R., Cordingley, J., Lee, M. A., Huszar, L., Moddle, G., Singh, R., KIRALY, L., \& RANKIN, J. G. (1981). Cerebral atrophy and functional deficits in alcoholics without clinically apparent liver disease. Neurology, 31, 377-385.

Damasio, H. (1983). A computed tomographic guide to the identification of cerebral vascular territories. Archives of Neurology, 40, 138-142.

Gruneberg, M. M. (1983). Memory processes unique to humans. In A. Mayes (Ed.), Memory in animals and man (pp. 253-281). London: Van Nostrand.

HaRT, J. T. (1965). Memory and the feeling-of-knowing experience. Journal of Educational Psychology, 56, 208-216.

Hays, W. L. (1973). Statistics for the social sciences (2nd ed.). New York: Holt, Rinehart \& Winston.

HeAton, R. K. (1981). Wisconsin card sorting test manual. Odessa, FL: Psychology Assessment Resources.

INCISA DELla RoccheTta, A. (1986). Classification and recall of pictures after unilateral frontal or temporal lobectomy. Cortex, 22, 189-211.

Jacobson, R. R., Lishman, W. A. (1987). Selective memory loss and global intellectual deficits in alcoholic Korsakoff's syndrome. Psychological Medicine, 17, 649-655.

Janowsky, J. S., Shimamura, A. P., Kritchevsky, M., \& SQuire, L. R. (in press). Cognitive impairment following frontal lobe damage and its relevance to human amnesia. Behavioral Neuroscience.

Jetter, W., Poser, U., Freeman, R. B., JR., \& Markowitsch, J. H. (1986). A verbal long-term memory deficit in frontal lobe damaged patients. Cortex, 22, 229-242.

LURIA, A. R. (1966). Higher cortical functions in man. New York: Basic Books.

Matris, S. (1976). Dementia rating scale. In R. Bellack \& B. Karasu (Eds.), Geriatric psychiatry (pp. 77-121). New York: Grune \& Stratton.

Milner, B., Petrides, M., \& Smith, M. L. (1985). Frontal lobes and the temporal organization of memory. Human Neurobiology, 4, 137-142.

Nelson, T. O. (1984). A comparison of current measures of the accuracy of feeling-of-knowing predictions. Psychological Bulletin, 95, 109-133.

Nelson, T. O. (1988). Predictive accuracy of the feeling of knowing across different criterion tasks and across different subject populations and individuals. In M. M. Gruneberg, P. E. Morris, \& R. N.
Sykes (Eds.), Practical aspects of memory; Current research and issues (Vol. 1, pp. 190-196). New York: Wiley.

Nelson, T. O., Gerler, D., Narens, L. (1984). Accuracy of feelingof-knowing judgments for predicting perceptual identification and relearning. Journal of Experimental Psychology: General, 113, 282-300.

Nelson, T. O., \& NARENS, L. (1980). A new technique for investigating the feeling of knowing. Acta Psychologica, 46, 69-80.

Petrides, M., \& Milner, B. (1982). Deficits on subject-ordered tasks after frontal- and temporal-lobe lesions in man. Neuropsychologia, 20, 249-262.

Shallice, T., \& Evans, M. E. (1978). The involvement of the frontal lobes in cognitive estimation. Cortex, 14, 294-303.

Shimamura, A. P., Jernigan, T. L., Seuire, L. R. (1988). Radiological (CT) findings in patients with Korsakoff's syndrome and their relationship to memory impairment. Journal of Neuroscience, 8, $4400-4410$.

Shimamura, A. P., Landwehr, R. F., \& Nelson, T. O. (1981). FACTRETRIEVAL: A program for assessing someone's recall of general-information facts, feeling-of-knowing judgments for nonrecalled facts, and recognition of nonrecalled facts. Behavior Research Methods \& Instrumentation, 13, 691-692.

Shimamura, A. P., a Squire, L. R. (1986). Memory and metamemory: A study of the feeling-of-knowing phenomenon in amnesic patients. Journal of Experimental Psychology; Learning, Memory, \& Cognition, 12, 452-460.

Smith, M., Milner, B. (1984). Differential effects of frontal-lobe lesions on cognitive estimation and spatial memory. Neuropsychologia, 22, 697-705.

SMITH, M. L., MiLner, B. (1988). Estimation of frequency of occurrence of abstract designs after frontal or temporal lobectomy. Neuropsychologia, 26, 297-306.

SQuire, L. R. (1982). Comparisons between forms of amnesia: Some deficits are unique to Korsakoff's syndrome. Journal of Experimental Psychology: Learning, Memory, \& Cognition, 8, 560-571.

Squire, L. R., Amaral, D. G., Zola-Morgan, S., Kritchevsky, M., \& Press, G. (1987). New evidence for brain injury in the amnesic patient N.A. based on magnetic resonance imaging. Society for Neuroscience Abstracts, 13, 1454.

Squire, L. R., \& Shimamura, A. P. (1986). Characterizing amnesic patients for neurobehavioral study. Behavioral Neuroscience, 100, 866-877.

SQUIRE, L. R., \& Zouzounis, J. A. (1988). Self-ratings of memory dysfunction: Different findings in depression and amnesia. Journal of Clinical \& Experimental Neuropsychology, 10, 727-738.

TALLAND, G. A. (1965). Deranged memory; A psychonomic study of the amnesic syndrome. New York: Academic Press.

WECHSLER, D. (1981). Manual for the Wechsler Adult Intelligence ScaleRevised. New York: Psychological Corp.

WECHSLER, D. (1987). Wechsler memory scale-Revised. San Antonio, TX: Harcourt Brace Jovanovich.

(Manuscript received April 20, 1988; revision accepted for publication August 15,1988 .) 